\title{
External DC defibrillation during open heart surgery
}

\author{
M. V. B R A I M B I D GE, A. J. CLEMENT, E. YALAV, \\ and A. ERSOZ \\ Department of Cardiothoracic Surgery, St. Thomas' Hospital, London S.E.1
}

\begin{abstract}
A technique of external DC defibrillation during open heart surgery is described. It has proved of value in second operations and has been consistently successful except in some patients with aortic valve disease and massive left ventricles.
\end{abstract}

External DC defibrillation at the time of open heart surgery was shown to be practical by Rastelli in 1968 and has been adopted by many units since (Rastelli, Hoeksema, McGoon, and Kirklin, 1968). At St. Thomas' Hospital it has been used as the routine defibrillation technique and this communication reports a study of how effective it has been.

\section{METHOD}

The equipment used has been made by Cardiac Recorders Ltd. ${ }^{1}$, the posterior plate being their standard posterior plate which is put under the right hemithorax and the patient's weight is allowed to rest on it (Fig. 1). The anterior plate is a specially developed low profile plate which is attached over the

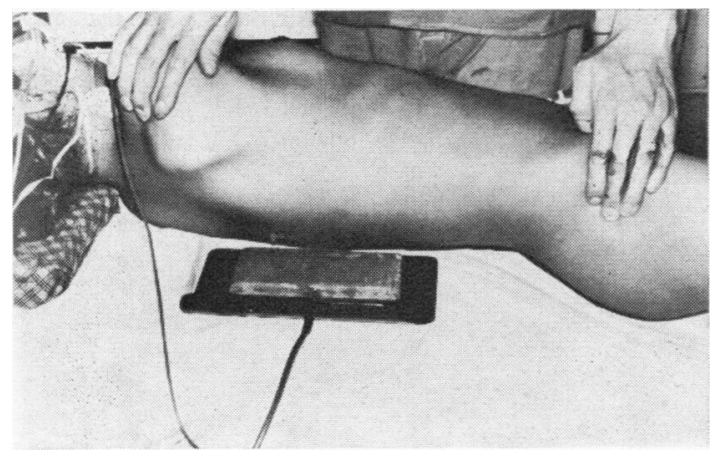

FIG. 1. Standard Cardiac Recorders DC defibrillation plate placed behind the right hemithorax.

apex of the heart and fixed in position with adhesive tape which is then covered with sterile plastic sheet (Figs 2 and 3). Initially, between 150 and $250 \mathrm{~J}$ shocks were used but it was found that the most consistently successful discharge for large hypertrophied hearts was around $350 \mathrm{~J}$.

${ }^{2}$ Cardiac Recorders Ltd., 375 City Road, London E.C.1
CLINICAL STUDY Eighty-six consecutive prosthetic valve replacements were studied. Cardiopulmonary bypass was established in each with disc or bubble oxygenators, reducing the temperature of the patient to $30^{\circ} \mathrm{C}$. The aorta was clamped in each case, coronary perfusion being carried out for 3 minutes at the end of each 10-minute interval by release of the aortic clamp, except when the aortic valve was being operated on when an indwelling left coronary artery

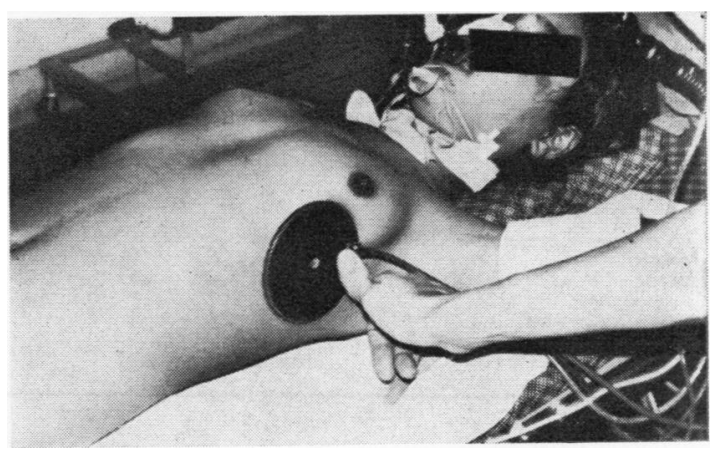

FIG. 2. Low profile plate over apex.

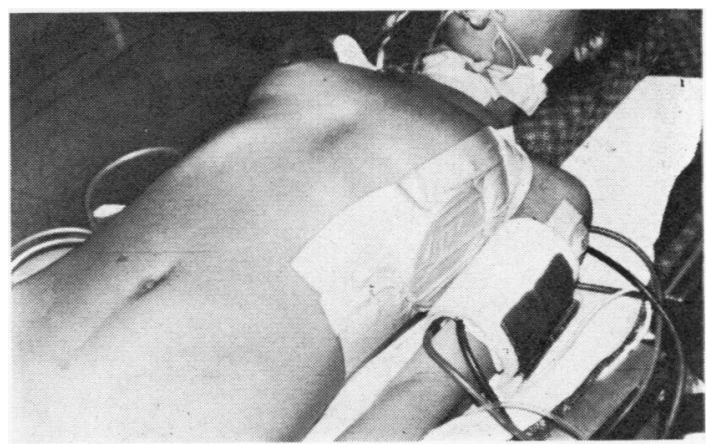

FIG. 3. Low profile plate fixed in position with adhesive tape. 
cannula allowed continuous left coronary perfusion in addition to intermittent right coronary artery perfusion.

In 26 patients the heart beat throughout the procedure. Sixty patients developed ventricular fibrillation. Of these, 11 had mitral valve replacements, 34 aortic valve replacements, and 15 aortic and mitral valve replacements.

The effectiveness of external defibrillation in these 60 patients was analysed by the number of shocks that had been recorded as having been used before a sustained coordinated beat was obtained. This necessarily underrated the value of external DC defibrillation as it did not take into account how many times the ventricle was successfully defibrillated but again reverted to ventricular fibrillation.

Nevertheless, 35 of the 60 patients were converted to a sustained, coordinated beat by a single DC shock. Ten of the remaining 25 responded to two shocks and three patients to three or more shocks (Table). Twelve, however, failed to sustain a coordinated beat with external defibrillation. Eleven of these were in the group of grossly hypertrophied left ventricle due to aortic valve disease and in four of these the plates were positioned too far posteriorly, which was an error in the early part of the series. Internal defibril-

T A B L E

EFFECTIVENESS OF EXTERNAL DEFIBRILLATION IN 60 PATIENTS WITH VENTRICULAR FIBRILLATION

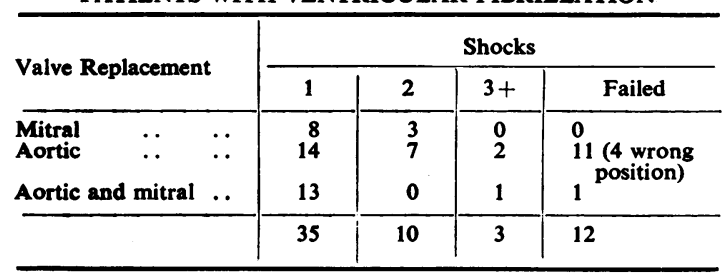

lation was used if three external shocks failed to pros duce a consistent coordinated beat, though this alse was not always immediately successful.

\section{CONCLUSION}

External DC defibrillation can be both effective and valuable. It is effective, that is, except in the grossly hypertrophied ventricle of aortic valve disease in which a percentage of failures may be obtained and internal DC defibrillation may $b \vec{E}$ more effective. External defibrillation is invaluablis in second operations when only the aorta and right and left atria need to be dissected with thie ventricles left entirely undisturbed. The incidencer of a low cardiac output before going on bypas? induced by mobilization of the left ventricle and of haemorrhage following bypass is thereby re duced. External defibrillation has also prevente the not uncommon recurrence of ventricular fibrito lation when internal defibrillator plates are removed from the pericardium. It also reduces damage to the myocardium produced by heap which has been reported following repeated highs voltage internal DC defibrillation (Rivkin, 1963 MacLean and van Tyn, 1961).

\section{REFERENCES}

MacLean, L. D., and van Tyn, R. A. (1961). Ventriculā defibrillation. J. Amer. med. Ass., 175, 471.

Rastelli, G. C., Hoeksema, T. D., McGoon, D. C., and Kirklin, J. W. (1968). Experimental study and clinica appraisal of external defibrillation with the thora open. J. thorac. cardiovasc. Surg., 55, 116.

Rivkin, L. M. (1963). The defibrillator and cardiac burn\$ J. thorac. cardiovasc. Surg., 46, 755. 